\title{
Left Atrial Appendage Aneurysm - Echocardiografic Diagnostic
}

\author{
Viviane Cordeiro Veiga, Salomón Soriano Ordinola Rojas, Amilton Silva Júnior, Marcelo Luiz Patrício, Elias César Hauy \\ Marum, Henry Abensur \\ Setor de Ecocardiografia Adulto - Real e Benemérita Associação Portuguesa de Beneficência - São Paulo, SP - Brazil
}

The left atrial appendage aneurysm is a rare condition that frequently manifests itself by heart arrhythmias or thromboembolism. We report the case of a patient with left atrial appendage aneurysm, diagnosed by echocardiography and submitted to surgical resection.

\section{Introduction}

The aneurysm of left atrial appendage is an extremely rare condition, described for the first time in 1938 by Semans \& Taussig, quoted by Victor and Nayak ${ }^{1}$. It occurs frequently associated to alterations in the mitral valve and manifests with heart arrhythmias or thromboembolic phenomenon.

The objective of this work is to present the case report of left atrial appendage aneurysm diagnosed by echocardiography.

\section{Case report}

Patient of 28 years, male, began to feel palpitations two years ago, with progressive worsening of the symptoms. Sought medical service, when through electrocardiogram, ectopic atrial rhythm was verified, and, through thorax X-ray, incurvation of the left heart silhouette, was verified. Transthoracic echocardiogram was requested.

Through the transthoracic echocardiography a cystic structure was seen in area adjacent to the left chambers (fig. 1). The ventricular function was preserved and the heart valves presented normal morphology, no reflux detected in the study with Doppler. Accomplishment of transesophageal echocardiography was suggested for better evaluation of the cystic image.

In the transesophageal echocardiogram, the presence of

\section{Key words}

Aneurysm; atria; echocardiography/diagnosis.

\section{Mailing address: Viviane Cordeiro Veiga •}

Al. Hungria, 89 - 06474-140 - Barueri, SP - Brazil

E-mail: vcveiga@cardiol.br

Manuscript received May 07, 2007; revised manuscript received August 05, 2007; accepted October 01, 2007. left atrial appendage aneurysm could be verified, without thrombus in its interior, measuring $7.0 \mathrm{~cm}$ approximately in its longitudinal axis (fig. 2). On that occasion, the patient was in atrial flutter rhythm.

The patient was submitted to surgical correction of the left atrial appendage aneurysm with ablation for treatment of the atrial flutter, with no intercurrence. He left the Intensive Therapy Unit on the second day of postoperative, with sinusal rhythm, in good clinical conditions, and, later, discharged from hospital.

\section{Discussion}

Left atrial appendage aneurysm is an extremely rare condition, described for the first time in 1938 by Semans \& Taussig, quoted by Victor and Nayak ${ }^{1}$.

More commonly, it is diagnosed between the second and fourth decades of life ${ }^{1}$, after episode of thromboembolism or cardiac arrhythmia ${ }^{2-5}$, as in our patient. In asymptomatic patients, the diagnosis can be accomplished by observation of radiographic alterations, as the prominence of the left heart border, with indications of complementary diagnosis with Doppler echocardiography or nuclear magnetic resonance ${ }^{2}$.

The presence of left atrial appendage aneurysm is usually associated to alterations in the mitral valve or to defects of the pericardium. Isolatedly, it is uncommon ${ }^{5}$.

The echocardiography remains an excellent method in the evaluation of the left atrial appendage aneurysms, especially via transesophagus ${ }^{1,6,7}$. Habitually, the transthoracic echocardiogram allows the visualization of cystic structure connected to the left atrium, besides the evaluation of comittment of associated mitral valve ${ }^{5}$. The transesophageal echocardiogram allows the visualization of left atrial appendage, due to the proximity of the esophagus to that structure, and the verification for trombus within.

Besides these methods, for diagnostic definition, magnetic nuclear resonance and angiography ${ }^{2}$ can be used. For the patient in this case, the echocardiographic diagnosis was sufficient enough for indication of surgery.

Considering the complications that can arise of this abnormality, especially the heart arrhythmias and the thromboembolitic phenomenon, the surgical resection is recommended as soon as the diagnosis is established, with good prognosis for the patient ${ }^{7}$.

\section{Conclusion}

The transesophageal echocardiography was the diagnostic 


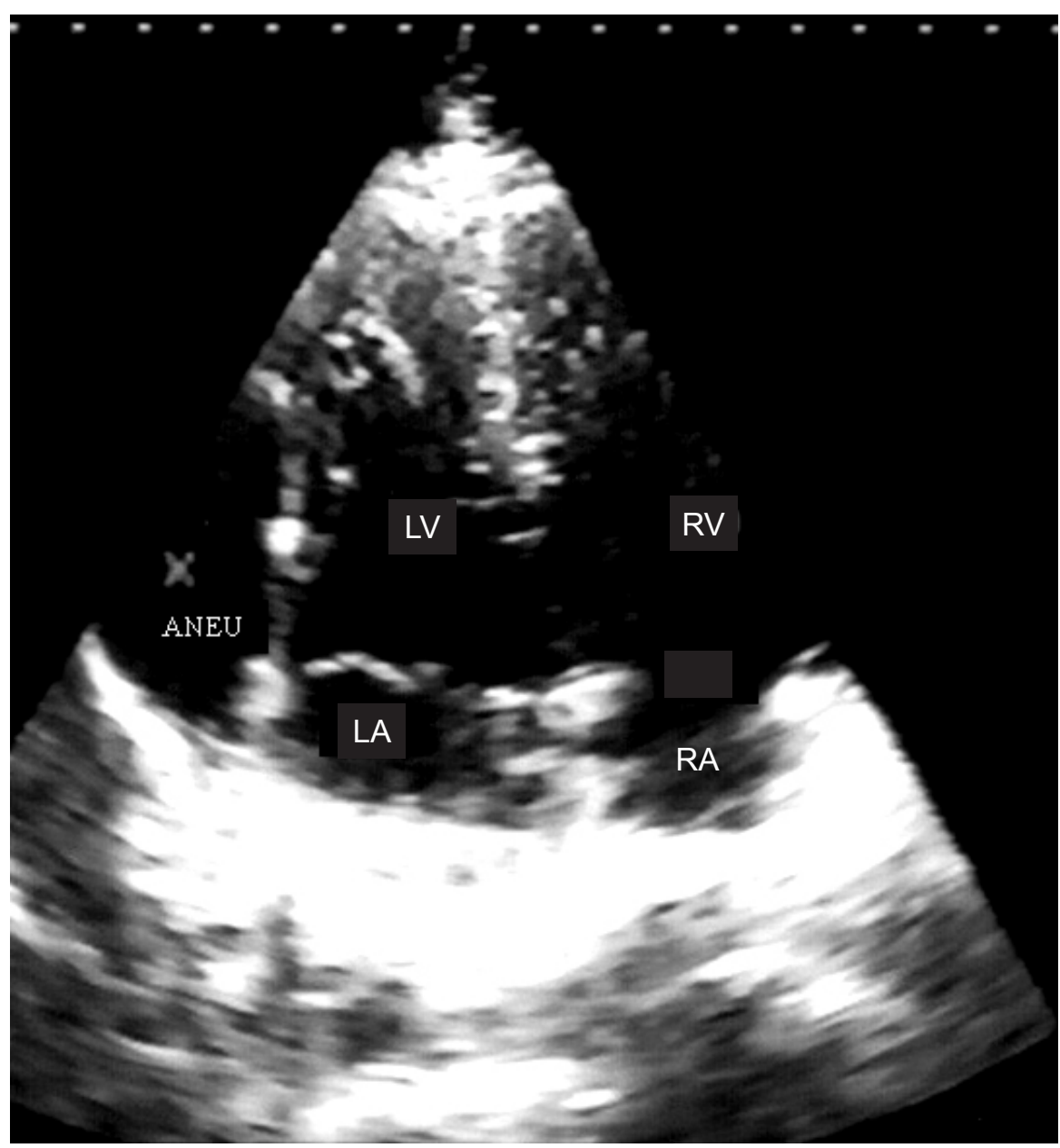

Figure 1 - Transthoracic echocardiography showing cystic image (ANEU) adjacent to the left chambers. $L V$ - left ventricle; $R V$ - right ventricle; LA - left atrium; LA - right atrium

exam in patient with left atrial appendage aneurysm.

\section{Potential conflict of interest}

No potential conflict of interest relevant to this article was reported.

\section{Sources of funding}

There were no external funding sources for this study.

\section{Study association}

This study is not associated with any graduation program. 


\section{Case Report}

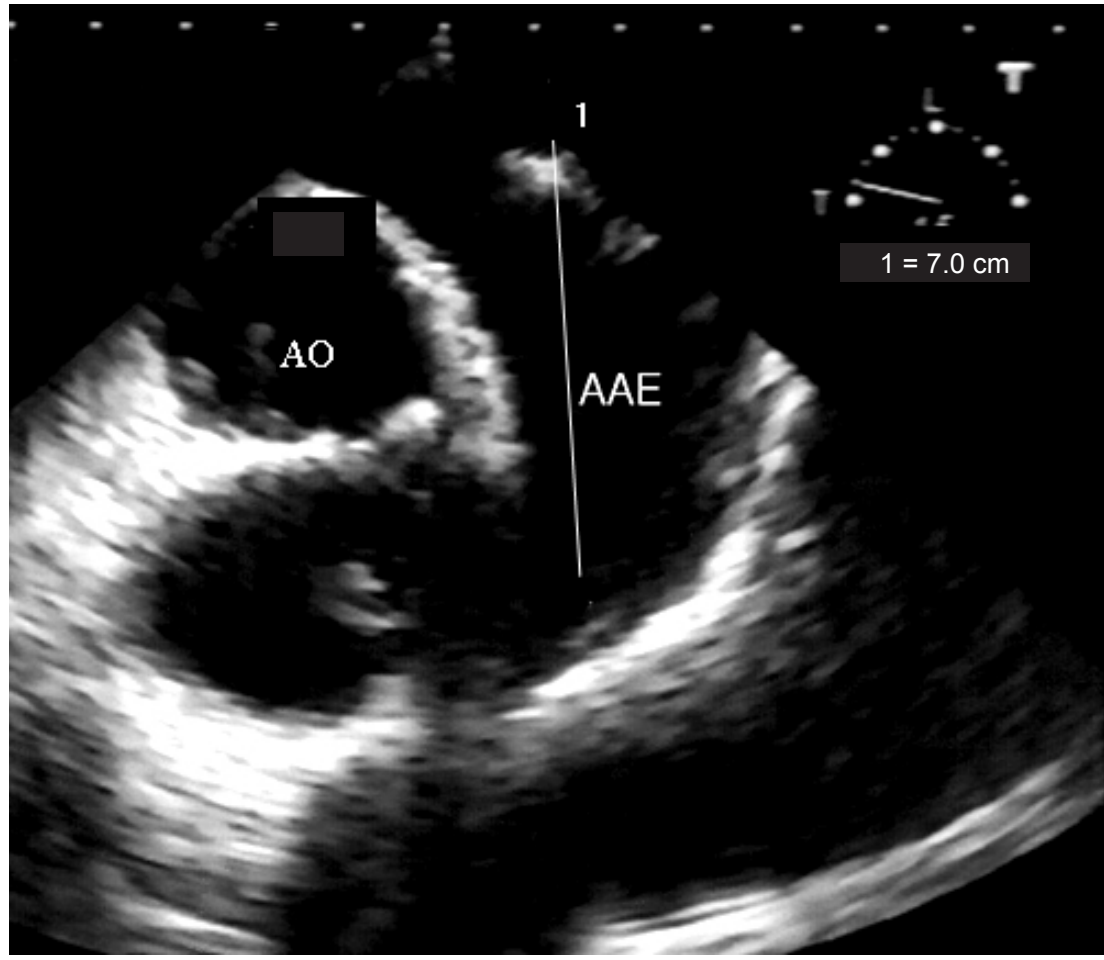

Fig. 2 - Transesophageal echocardiography visualizing the left atrial appendage, that is aneurysmal (AAE). AO - aorte.

\section{References}

1. Victor S, Nayak V. Aneurysm of the left atrial appendage. Tex Heart Inst J. $2001 ; 28$ (2): 111-8.

2. Vagefi PA, Choudhry M, Hilgenberg AD. Excision of an aneurysm of the left atrial appendage. J Thorac Cardiovasc Surg. 2007; 133: 822-3.

3. Kühn A, Schreiber C, Vogt M. Congenital left atrial appendage aneurysm in a 2-year-old boy. Eur Heart J. 2005; 27 (8): 959.

4. Chockalingam A, Alagesan R, Nandakumar M, Gnanavelu G. Massive left atrial appendage aneurysm presenting as supraventricular tachycardia. Indian Heart J. 2003; 55: 379-81.
5. Bueno RM, Cerdeira Jr M, Abensur H, Silva Jr A, Calil OA, Ávila Neto V, et al. Defeito do anel fibroso mitral posterior com aneurisma de átrio esquerdo e insuficiência mitral: tratamento cirúrgico com sucesso. Rev Bras Cir Cardiovasc. 1999; 14 (4): 348-54.

6. Tanoue Y, Kado H, Shiokawa Y, Sagawa K. Left atrial appendage aneurysm in a child. Ann Thorac Surg. 2004; 77: 721-3.

7. Ulucam M, Muderrisoglu H, Sezgin A. Giant left atrial appendage aneurysm: the third ventricle. Int J Cardiovasc Imaging. 2005; 21: 225-30. 